\title{
Chemical element detection in thin sections of soils with the Laser Microprobe Mass Analyzer (LAMMA 500)
}

\author{
E. B. A. Bisdom 1 , S. Henstra ${ }^{2}$, A. Jongerius ${ }^{1}$, H. J. Heinen ${ }^{3}$ and S. Meier ${ }^{3}$ \\ ${ }^{1}$ Soil Survey Institute, P.O. Box 98, 6700 AB Wageningen, Netherlands \\ ${ }^{2}$ Technical and Physical Engineering Research Service, P.O. Box 356, 6700 AJ Wa- \\ geningen, Netherlands \\ ${ }^{3}$ Leybold-Heraeus Comp., D-5000 Köln, Federal Republic of Germany
}

Accepted: 30 October 1980

Key words: Laser Microprobe Mass Analyzer (LAMMA 500), submicroscopic techniques, thin sections of soil, weathered granite, titanium, Ion Microprobe Mass Analyzer (IMMA), Laser Microspectral Analyzer (LMA).

\section{Summary}

Components from thin sections of soils developed in weathered granite have been analysed with the Lazer Microprobe Mass Analyzer (LAMMA 500). Fragments of thin sections were cut loose from the glass on which they were mounted, put into socalled sandwich grids, and shot through with the laser from the edges inwards (laser milling), using the laser light at grazing incidence. Laser-induced mass spectra of secondary titanium compounds and other constituents in the weathered granite were obtained in this manner. Positive and negative laser desorption mass spectra were recorded with such a speed and accuracy that in spite of the relatively large volume of analysed materials, minute changes in composition could be detected over very short distances. This allowed, for instance, total chemical element analysis of spots in which titanium compounds concentrated during weathering, giving information on changes in pureness of especially amorphous and semi-crystalline materials at such places. Light microscopic observations of the target materials combined with LAMMA techniques may thus provide a method by which one can analyse minute differences in chemical composition over short distances in the thin section depending on the type material being investigated. A table has been provided in which characteristic analysis possibilities of the Ion Microprobe Mass Analyzer (IMMA), Laser Microspectral Analyzer (LMA) and Laser Microprobe Mass Analyzer (LAMMA 500) are compared. 


\section{Introduction}

The present experiments with the Laser Microprobe Mass Analyzer (LAMMA 500) form part of a series of tests for finding a combination of research techniques enabling an in situ microanalysis of all chemical elements in thin sections of soil samples prepared according to the methods described by Jongerius \& Heintzberger (1963, 1975).

This is the fourth paper in a series published in the Netherlands Journal of Agricultural Science. The series started with the application of SEM-EDXRA, a combination of scanning electron microscopy and energy dispersive X-ray analysis (Bisdom et al., 1975). Principles of this method have already been discussed by Henstra et al. (1973) in a short paper. With SEM-EDXRA all chemical elements above atomic number 11 (sodium), present in quantities larger than those of trace elements, could be detected. The second paper concerned a comparison of the electron microprobe analyzer (EMA) and SEM-EDXRA. EMA is capable of analysing all elements with an atomic number above boron $(Z=5)$ and therefore theoretically able to detect and quantify N, O and C. Organic and mineral materials were used in this experiment and it was found that $\mathrm{N}$ was not detectable, whereas $\mathrm{O}$ and $\mathrm{C}$ could not be specifically attributed to the organic parts of the sample (Bisdom et al., 1976). Consequently, another instrument had to be chosen capable of determining both light and heavy elements in thin sections of soils. The ion microprobe mass analyzer (IMMA) was selected for this purpose and the experiment was done on clayified root material. Results were published in a third paper by Bisdom et al. (1977). In another paper by Bisdom \& Jongerius (1978), more emphasis was given to the genetic interpretation of results with IMMA.

Ion microprobe mass analysis offers six features: elemental analysis, trace concentrations, trace amounts, depth concentration profiling, isotopic analysis and compound analysis (Liebl, 1975). Using IMMA, trace elements in a thin section can be studied. Due to the design of IMMA, analogous to the electron microprobe $\mathrm{X}$-ray analyzer (EMA), both ion images and positive and negative ion spectra can be made.

The results of the IMMA experiments were promising for future research of thin sections of soils and also, attention was concentrated on the possibilities of ion detection and portrayal with a mass spectrometer. Consequently, interest was aroused for instruments which offered possibilities of investigating ions set free from thin sections by way of mass spectrometry and, when possible, with quick sample handling. The new microprobe mass analyzer (LAMMA 500) made by the Leybold Heraeus Company was chosen on the basis of this idea and investigated.

\section{Laser ion probe microanalysis}

\section{Previous studies on materials other than soil}

Laser ion probe microanalysis has been done with the laser microprobe mass analyzer (LAMMA 500). Detailed technical descriptions of this instrument and its principles have been given by Hillenkamp et al. (1975), Heinen et al. (1978), Kaufmann et 
al. (1978) and Wechsung et al. (1978). LAMMA has been applied to various subjects, e.g. biomedical (Seydel \& Heinen, in press; Kaufmann et al., 1979; Heinen et al., in press $a$ ), organic and inorganic compounds (Heinen et al., in press $b$ ), various particles (Kaufmann \& Wieser, in press), and isotopes (Englert \& Herpers, 1980).

Most of the applied studies involved very thin sections of $1 \mu \mathrm{m}$ or less. Heinen et al. (in press $b$ ) have reported, however, that particles with diameters up to several millimeters can be analysed by shooting onto the visible edges with laser light at grazing incidence; a method which was also used for this experiment with materials in thin sections of soils. Information on the results of this experiment will follow below after some physical principles and a technical description of the LAMMA instrument have been given. Some of the results from experiments of the above mentioned authors have been included, especially the work of Kaufmann et al. (1979) and Heinen et al. (in press $b$ ).

\section{Physical principles}

The analysis of a microvolume of a solid sample is done by laser light in the laser microprobe mass analyzer (LAMMA 500). Power densities of $10^{7}$ to $10^{11} \mathrm{~W} / \mathrm{cm}^{2}$ are used during $15 \mathrm{~ns}$ for this type of analysis. At higher field strengths (power density) of up to $10^{14} \mathrm{~W} / \mathrm{cm}^{2}$ the laser pulse can even cause atomic fission of the ionized particles in the plasma, formed after impact of the beam onto solid state matter. In LAMMA, however, a maximum of $10^{12} \mathrm{~W} / \mathrm{cm}^{2}$ is reached. Focusing of a laser beam can be done with optical lenses and a spot size of 0.5 to $1 \mu \mathrm{m}$ is usually obtained. The spot size is small when a small wavelength is used, viz UV light with $265 \mathrm{~nm}$ frequency. In the actual instrument a frequency-quadrupled $\mathrm{Nd}-\mathrm{Yag}$ laser operates and this gives an available energy of about $100 \mu \mathrm{J}$ at the said wavelength. The use of small wavelength UV light also enhances the specific absorption of materials. Such a high absorption is important, because it restricts the interaction of the laser light and the sample area to a small volume. The result is an ultimate confinement of the places of ion formation and a sufficiently high excitation of the microvolume to give a characteristic mass spectrum.

The laser pulse instantaneously evaporates microvolumes of sample material after irradiation and no disturbing heat flow effects to the area surrounding an analyzed microvolume have been detected so far. A biological specimen with a thickness of about $0.5 \mu \mathrm{m}$ and an applied laser spot size of 0.5 to $1 \mu \mathrm{m}$ will lose approximately $10^{-12}$ to $10^{-13} \mathrm{~cm}^{3}$ of sample volume. Thicker particles of up to several millimeters need a number of shots before the laser beam can pass through completely. Depending on the specimen, the increase of crater depth is between 0.1 and $0.5 \mu \mathrm{m}$ after each shot, thereby allowing a rough type of depth profiling. Detection limits of LAMMA are such that $\mathrm{mg} / \mathrm{kg}$ and even $\mu \mathrm{g} / \mathrm{kg}$ concentrations can often be demonstrated in a sample, i.e. as little as $10^{-18}$ to $10^{-20} \mathrm{~g}$ absolute.

Laser-induced ionization yields positive and negative ion signals of about equal intensities which is different from most of the commonly used ionization methods in mass spectrometry. It was also found that the intensity of the signal for positive ions primarily depends on their ionization potential, whereas this is dependent on the electron affinity for negative ions. The target matrix itself has little influence on the 
signal intensity of atomic ions when compared to other methods, e.g. secondary ion mass spectrometry. However, the energy deposited in the excited microvolume influences the total amount of ions generated and the relative intensities in the mass spectra. Generally, the higher the energy absorption the more the small mass ions are favoured.

Some general observations have already been made on the behaviour of irradiated matter when affected by increasing intensities of the laser beam. In general, features such as ion yields, initial energy distribution of the ions after excitation, and fragmentation of molecules, depend on the laser parameters, particularly the irradiance in the focus, i.e. $10^{7}$ to $10^{11} \mathrm{~W} / \mathrm{cm}^{2}$ in LAMMA 500. Low power densities of the laser beam induce thermal processes which lead to the melting or evaporating of part of the sample. As a result of thermal ionization, alkali ions such as $\mathrm{Na}^{+}$and $\mathrm{K}^{+}$can be desorbed. Inorganic and organic ions are desorbed when the power density is increased above a certain level. The desorbed ions strongly correlate with the chemical nature of the investigated material, especially partly precharged molecules in a solid. A further increase of the laser power density induces a kind of microplasma which leads to a strong degradation of molecular entities. Atomic ions are formed which are only weakly dependent on the chemical matrix. Shielding effects from plasma space charges usually prohibit complete atomization. The high degree of excitation at higher power densities also allows the establishment of a concept of relative sensitivity coefficients for most elements.

A number of peaks are virtually always present in LAMMA spectra, viz $\mathrm{Na}^{+}, \mathrm{K}^{+}$ and $\mathrm{Ca}^{+}$, and $\mathrm{C}_{2}^{-}, \mathrm{C}_{2} \mathrm{H}^{-}, \mathrm{CN}^{-}, \mathrm{OCN}^{-}$corresponding to peaks at $\mathrm{m} / \mathrm{e} 24,25,26$ and 42 in negative spectra. A possible explanation of this phenomenon may be that these ions represent very stable end products of plasma reactions. However, sodium and other cations like magnesium and calcium have a low ionization potential which means that the sensitivity of detection by LAMMA is extremely good. Elements such as $\mathrm{Zn}, \mathrm{Hg}, \mathrm{Cl}$ and $\mathrm{P}$ have high ionization energies and are therefore more difficult to detect. The elements $\mathrm{Cl}$ and $\mathrm{P}$, however, not only have a high ionization potential but also a high affinity for electron capture. They can therefore easily be detected in the spectrum of negative ions. This complementary aspect of mass spectra from positive and negative ions is important for the net result of sample analysis with LAMMA 500.

Generally, electropositive elements exhibit atomic ions in positive spectra and electronegative elements in negative spectra. Positive as well as negative ions are given by elements from the middle part of the periodic table. Molecular ions are formed in such a way that the electropositive elements dominate in the positive spectra and the electronegative in the negative spectra. Two modes of laser-induced ion generation from solid samples are commonly used, viz solid materials are atomized to a maximum degree whereby the analysed microvolume is excited to a microplasma with near-saturation absorption, and by the laser desorption (LD) mode in which the sensitivity of the ion detection system is increased to a maximum and the laser excitation reduced to a level at which only very few mass lines occur. The first method is used as a sensitive element microprobe for practically all elements of the periodic table, whereas the laser desorption method is applied to ionic and partially 


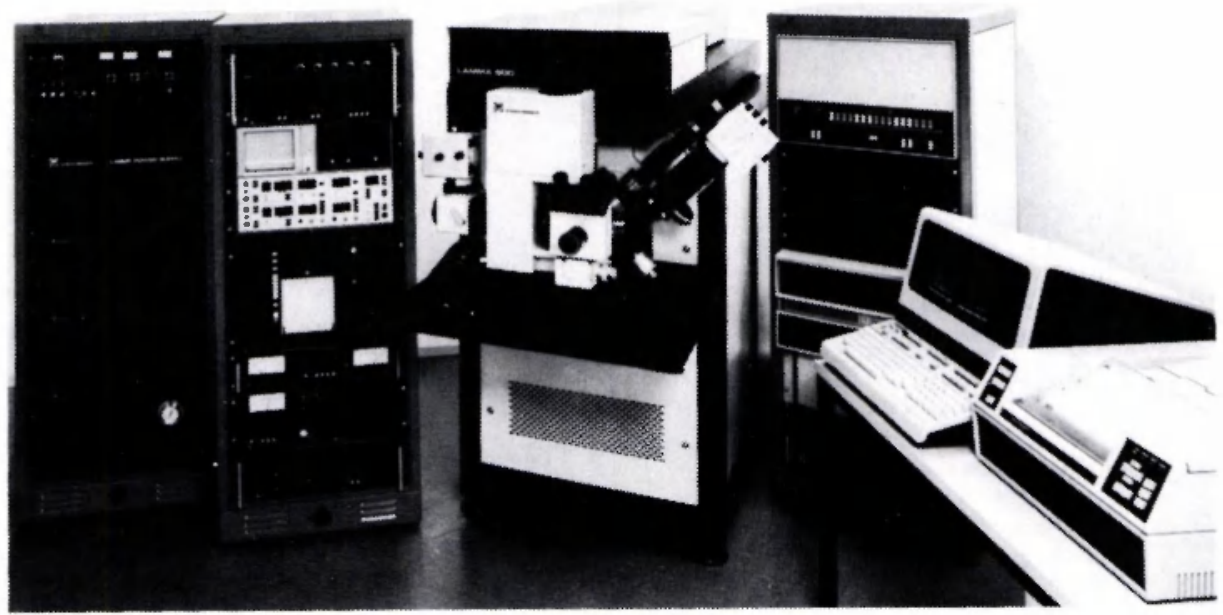

Fig. 1. The Leybold Heraeus Laser Microprobe Mass Analyzer (LAMMA 500).

ionic compounds such as salts, organic acids and bases. It was found that salt cations and bases appeared in the positive LD spectra, whereas salt anions and acids did so in the negative LD spectra.

\section{The LAMMA 500 instrument}

The laser microprobe mass analyzer (LAMMA 500) (Fig. 1) can briefly be described with the help of a diagram of the whole instrument (Fig. 2a) and an enlargement of the area in which the specimen is located (Fig. 2b). The laser beam is formed in a $\mathrm{Nd}$-Yag laser which generates frequency-quadrupled $(265 \mathrm{~nm}) \mathrm{UV}$ light. The beam of the pulsed laser is focused through a high power optical microscope onto the specimen to be analysed. Spatial resolution in both an optical and an analytical sense is limited by defraction to about $0.5 \mu \mathrm{m}$. The Helium-Neon laser, as distinct from the destructive Nd-Yag laser, allows the operator to view the target area by a red spot. Both the power Nd-Yag laser and the He-Ne laser are mounted horizontally on top of an optical platform. The alignment of the beams of the two lasers can be done using a system of adjustable mirrors. The laser light is then fed into the high power light microscope with a horizontal optical axis, to allow alignment with the axis of the time of flight spectrometer which is discussed below. This light microscope also makes viewing of the sample possible by either incident or transmitted light when no analysis with the laser is done. During analysis, however, the optical condensor in the vacuum underneath the sample is pneumatically exchanged for an electrostatic ion lens and the specimen can only be observed with incident illumination.

The analyzed specimen consisted in our case of materials in thin sections of soils, pieces of which were taken from the support glass and placed in so-called sandwich grids each wing of which consisting of a grid commonly used in transmission electron microscopy (TEM). The sandwich grid is subsequently placed beneath a thin $(0.15 \mathrm{~mm})$ quartz cover and in the vacuum of the instrument; a vacuum made by a 


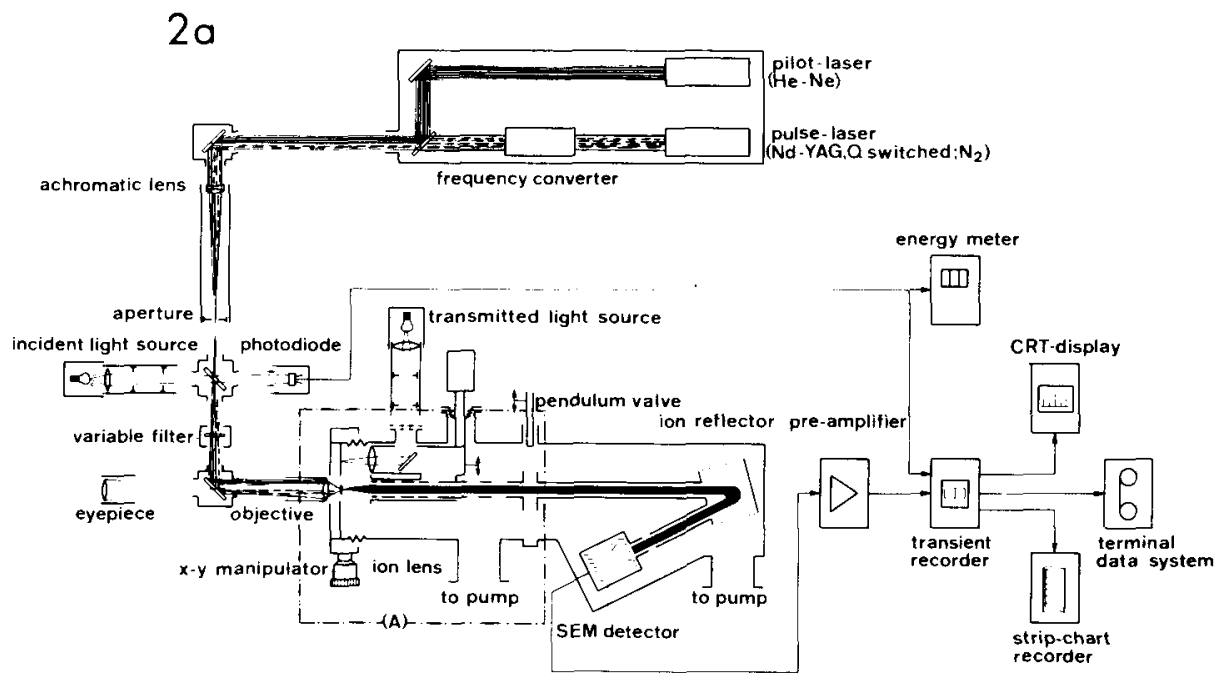

$2 b$

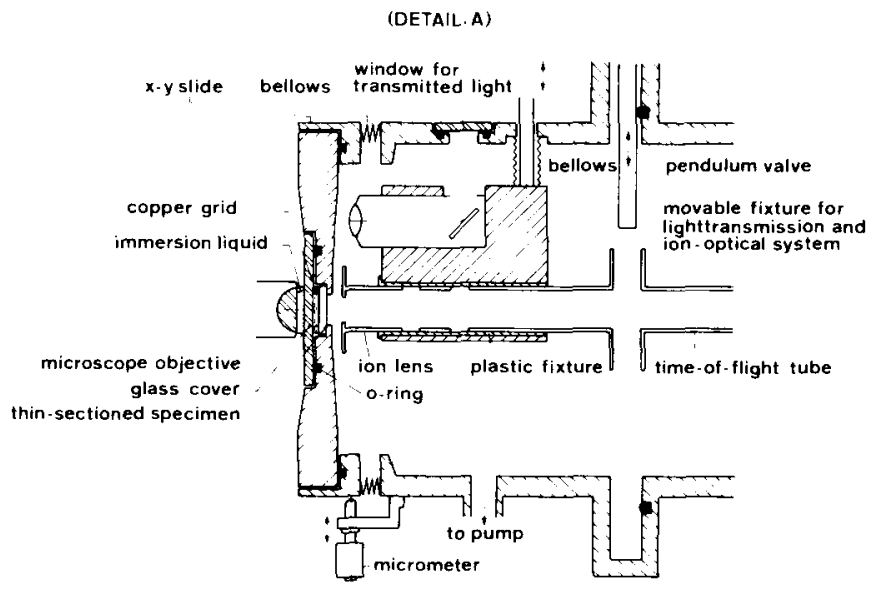

Fig. 2. Schematic diagram of the LAMMA 500 instrument (Fig. 2a) and of the specimen chamber (Fig. 2b). Compare text.

rotary pump in series with a turbomolecular pump which reaches a vacuum of $10^{-5}$ $\mathrm{Pa}\left(10^{-7} \mathrm{mbar}\right)$. The quartz cover is used as an optical window and a vacuum seal at the same time, a set-up which allows the use of light microscopic objectives made of quartz. The thickness of the thin section ranges from about 20 to $25 \mu \mathrm{m}$, a thickness too great for LAMMA to perforate with one or only a few shots. Total perforation 
Table 1. Comparison of some features important for the analysis of materials in thin sections of soil with the LMA, LAMMA and IMMA.

\begin{tabular}{llll}
\hline & LMA & LAMMA & IMMA \\
Ultra light elements & & & ++ \\
Bulk analysis (thicker than $2 \mu \mathrm{m})$ & + & + & ++ \\
Thin specimen (thin section $<2 \mu \mathrm{m})$ & + & ++ & ++ \\
Maximum size of specimen $\left(\mathrm{cm}^{2}\right)$ & $>4$ & $<0.04$ & $<+$ \\
Analysis on mounted thin section & possible & impossible & impossible \\
Continuous depth profiling & -- & -- & ++ \\
Step by step depth profiling $(>0.1 \mu \mathrm{m})$ & - & ++ & + \\
Localization (lateral resolution, lateral & & & + \\
resolving power $(<2 \mu \mathrm{m})$ & - & + & ++ \\
Isotopes & -- & -- & ++ \\
Surface analysis & -- & + & ++ \\
Sensitivity & - & + & + \\
Time necessary for specimen change & ++ & + & + \\
Portrayal of the spot which is analysed & + & -- & + \\
Destruction of sample material & -- & impossible & ++ \\
lon distribution images & impossible & ++ & ++ \\
Ion spectra (mass spectra) & impossible & + & + \\
Emission spectra & + & impossible & impossible \\
Pretreatment & not necessary & not necessary & necessary \\
Cost of the instrument & lowest & intermediate & highest \\
\hline
\end{tabular}

++ excellent; + sufficient; - insufficient; - - bad.

of the sample is necessary, however, because LAMMA - in contrast to laser microspectral analysis (LMA) (cf. Table 1) - detection with the mass spectrometer makes this necessary. Therefore, shooting with the laser beam is done on the thinner visible edges of the thin section and at grazing incidence. This gives LAMMA spectra as portrayed in Fig. 4. However, 'laser milling', in which the material is destroyed from the edges of the thin section inwards, can also be done. It requires some time but allows the analysis of materials situated at some distance from the edges, with or without an analysis of the intermittent soil constituents.

Ions are formed after laser impact in the sample material, by evaporation of microvolumes $\left(10^{-12}\right.$ to $\left.10^{-13} \mathrm{~cm}^{3}\right)$ due to irradiation. These ions can be detected and analysed with a 'time of flight (TOF) mass spectrometer'. The ion lens, which can be pneumatically exchanged for the optical condensor of the light microscope (cf. above), forms the accelerating part of the TOF mass spectrometer, viz to a uniform energy of the ions. After which time ions reach a field-free drift tube in which separation of the ions takes place according to their mass-dependent drift time. Separate ion packs subsequently reach the ion reflector which compensates for the spread of initial ion energy. The detection of these ions is done by an open secondary electron multiplier (SEM) which delivers an analogue signal at its output, the amplitude of which corresponds to the number of ions represented by each pack. The TOF mass spectrometer analyses all ions in one cycle, i.e. obtainment and recording occur simultaneously, which is an advantage when compared to other mass spectrometers. 
The system is fairly sensitive because roughly 10 per cent of the ions formed reach the detector of the TOF mass spectrometer. Mass resolution can reach 800 to $1000 \mathrm{~m} / \Delta \mathrm{m}$ and no energy filters are required. The spectrometer has a transient time of $11 \mu \mathrm{s}$ for $7 \mathrm{Li}$ and $60 \mu \mathrm{s}$ for $208 \mathrm{~Pb}$.

The output of the open secondary electron multiplier (SEM) is fed to a digital transient recorder of 2048 addresses with a dynamic range of 8 bit. This renders the most rapid point to point resolution of $10 \mathrm{~ns}$, which gives about 5 to 6 data points per mass signal (mass number 50). Subsequently, the stored mass spectrum can be processed by a computer or recorded by a Brush pen recorder to give the spectra of Fig. 4. Both positive and negative mass spectra were obtained from the investigated thin sections of soil materials, viz in situ weathered granitic rock.

\section{Features of LAMMA 500, LMA and IMMA}

A comparison of the features of the laser microprobe mass analyzer (LAMMA 500), the laser microspectral analyzer (LMA) and the ion microprobe mass analyzer (IMMA) is briefly made to allow discrimination of similarities and differences of the instruments (Table 1). This table is mainly meant for the user of these instruments and does not imply that a complete technical discrimination is given. Ultra-light elements such as $\mathrm{H}$ and Li are detected excellently with IMMA and LAMMA, but are impossible to analyse with LMA. The laser microspectral analyzer (LMA) is able to analyse thin specimens $(<2 \mu \mathrm{m})$ but is best equipped for bulk analysis of samples thicker than $2 \mu \mathrm{m}$. LAMMA is primarily built for analysis of specimens $<2 \mu \mathrm{m}$ but can also analyse thicker samples by shooting the laser beam onto the visible edges of the thin section at grazing incidence. IMMA, on the other hand, analyses the surface of samples and in doing so slowly destroys them. The instrument also requires polished thin sections of soils, which is not the case with LAMMA and LMA.

Table 1 demonstrates that most of the other analytical features offered by LMA cannot be compared with LAMMA and IMMA. LMA of fers the possibility of analysing emission spectra of ionized plasma captured by a spectrograph and subsequently recorded on a photographic plate, whereas the other two instruments have mass analyzers for the recording of ion spectra. The result is that the sensitivity of IMMA and LAMMA is much higher, helped by a superior detection and analysis system. The only similarity of LAMMA and LMA is therefore that both instruments use a laser beam for excitation purposes. The costs of LMA are, however, much lower and the sample - in our case a thin section of soil - can remain on the support glass. Analysis with LMA at the physics laboratory of Philips indicated that the instrument can be used for the detection of heavier elements in thin sections of soils. Additional data on LMA work in micromorphology can be found in an article by Bresson (1978) who also experimented on this sections with an ultra thin diameter. Trace amounts and trace concentrations, however, require instruments like LAMMA and IMMA in order to be recorded. The localization of LAMMA and IMMa is much better than LMA, i.e. $<2 \mu \mathrm{m} \varnothing$ for IMMA and LAMMA and about $15 \mu \mathrm{m} \varnothing$ for LMA.

Isotopes can be studied with all instruments except LMA, whereas depth profiling is only possible with IMMA as is the formation of an ion image. The analysed areas 
are gradually destroyed with IMMA, while LAMMA and LMA completely evaporate microvolumes which can afterwards be seen as craters in the sample. No pretreatment is necessary for samples analysed with LAMMA and LMA as far as thin sections of soils are concerned. IMMA, however, requires pretreatment - frequently with $\mathrm{Au}$ - for a better conduction of the surface and to prevent charging effects. To perform the analysis, a small part of the coating layer is sputtered away with the ion beam and the underlying soil material can thereafter be analysed.

The results of our experiments with LMA, LAMMA and IMMA on thin sections of soils indicate that all instruments serve certain purposes, but that the analytical possibilities of LMA are the smallest. LAMMA offers a far greater scale of possibilities and should be regularly used in micromorphological soil research of undisturbed materials. IMMA, however, offers additional features to LAMMA, viz surface analysis of the soil sample with a small depth penetration, ion imaging which gives the distribution of individual ions over a certain small area at the surface of the thin section, and the possibility of depth profiling in which very small volumes are destroyed at subsequent depths in the thin section. It may be concluded, therefore, that LMA is the cheapest and IMMA the most expensive instrument but that the additional costs are accompanied by important additional research possibilities.

\section{Example of the LAMMA 500 method}

Experiments were done with the laser microprobe mass analyzer (LAMMA 500) on thin sections of soils formed in weathered granite described by Bisdom (1967a, b). To allow a comparison of the results obtained with the LAMMA 500, weathering biotite was also examined with SEM-EDXRA. Interest was concentrated on Ticontaining amorphous materials from which a turbid type of secondary anatase developed (Bisdom, 1967b). The amorphous materials were present in the form of clouds which could be related to weathering biotite-vermiculite and the Ti contained in the crystal lattice of the original biotite and/or the rutile (sagenite) inclusions of this mineral. Minute and larger droplets could develop in the Ti-containing clouds, and secondary anatase $\left(\mathrm{TiO}_{2}\right)$ with a turbid appearance was observed to form from the droplets according to light microscopic observations. This possibility to recognize the Ti-containing clouds in the thin section also allowed easy localization with the LAMMA 500, an instrument which is also equipped with a light microscope.

Before the results of LAMMA experiments are discussed, some information concerning the SEM-EDXRA tests will be given. The application of the backscattered electron method (Bisdom and Thiel, 1981), rather than the commonly used secondary electron images, allowed a satisfactory portrayal of secondary Ti accumulations in the thin section (Figs. 3a-3b). The backscattered electron scanning images of weathering biotite-vermiculite were in turn easy to correlate with light microscopic observations. SEM-EDXRA measurements of the Ti-containing clouds revealed that the $\mathrm{Ti}$ content increased with the degree of crystallinity (Fig. 3c-3e). As will be indicated below, LAMMA experiments revealed the same results and trace elements could be localized in the Ti-containing amorphous materials.

Tests with the LAMMA 500 were conducted on three types of materials, viz unweathered, moderately altered and completely weathered biotite, usually giving sec- 

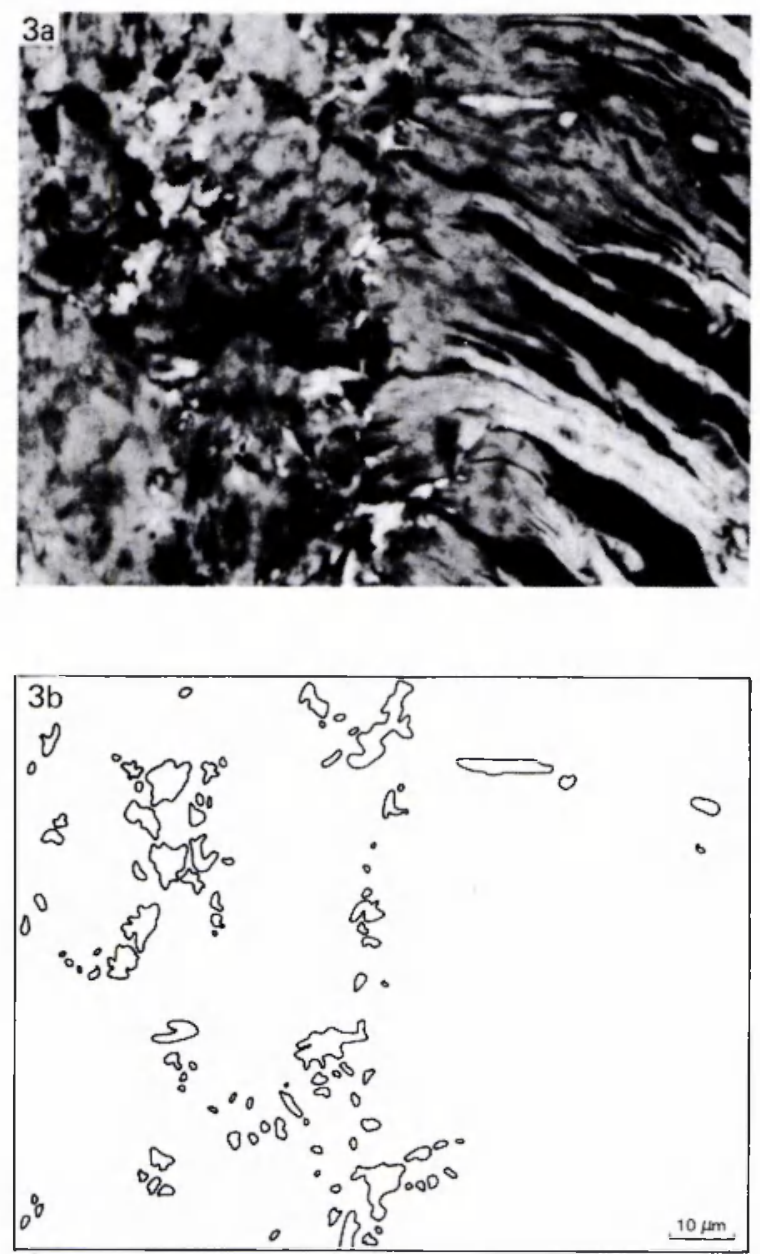

Fig. 3. Backscattered electron scanning image of weathering vermiculite-biotite into kaolinite and/or metahalloysite. Porous and still recognizable weathering vermiculite-biotite to the right and kaolinite and/or metahalloysite to the left (Fig. 3a), Distribution of $\mathrm{Ti}$ containing clouds and secondary anatase in Fig. 3a indicated schematically in Fig. 3b. EDXRA peaks of Fe-containing kaolinite and/or metahalloysite (Fig. 3c), of material in Ti-containing clouds (Fig. 3d), and of turbid secondary anatase (Fig. 3e). The $K \alpha$ peaks of $\mathrm{Si}, \mathrm{Ti}$ and $\mathrm{Fe}$ are indicated and $\mathrm{K} \beta$ peaks appear to the right of $\mathrm{K} \alpha$ ones, viz of $\mathrm{Ti}$ and $\mathrm{Fe}$. The $\mathrm{K} \alpha$ peak of $\mathrm{Al}$ is situated to the left of the Si K $\alpha$ one and not indicated. Please note that - for technical reasons - the abbreviations of the elements directly underneath the peaks have been placed somewhat to the right of their bases.
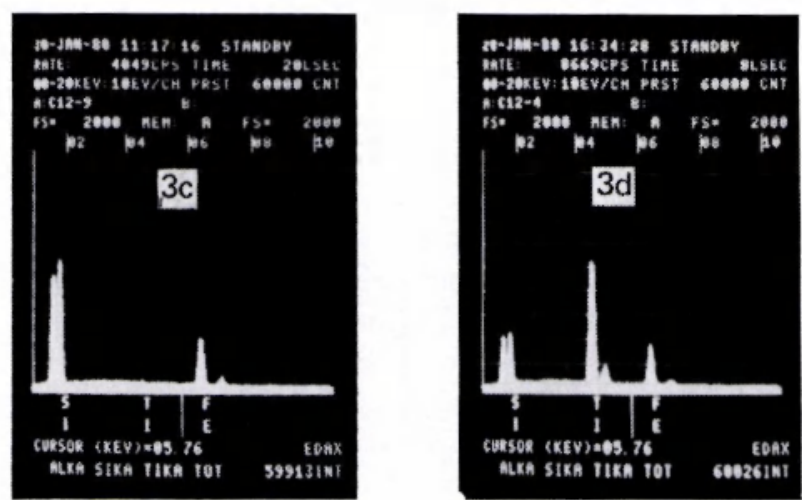

32

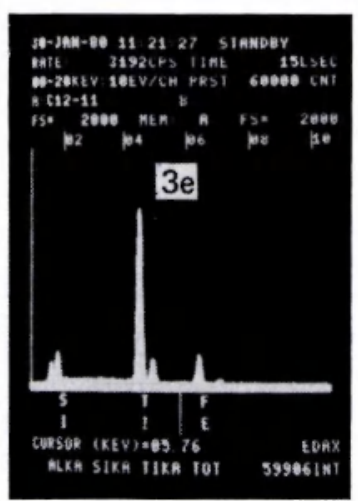

Neth. J. agric. Sci. 29 (1981) 
ondary clay minerals belonging to the kaolinite group as an end product of the weathering sequences. Three mass spectra of secondary ions are shown in Fig. 4 . These exhibit predominantly positive ions of $\mathrm{Mg}, \mathrm{Al}, \mathrm{Si}, \mathrm{K}, \mathrm{Ti}$ and $\mathrm{Fe}$. Negative mass spectra were also made but not shown; these are still difficult to interpret without proper standards and are not of fundamental importance for the weathering problem under consideration in this experiment. $\mathrm{O}, \mathrm{Na}$ and $\mathrm{Mn}$ were also found as positive ions in a number of shots, whereas $\mathrm{H}$ and $\mathrm{Li}$ were only measured at the edges of samples, representing a contamination feature. The latter two elements were absent as soon as the laser had penetrated the sample over a distance of about $1 \mu \mathrm{m}$. Another noteworthy contamination effect was given by sputtered particles which had landed on the cover glass. The result was the loss of symmetry of the $\mathrm{K}$ peak which exhibited an irregular and extended right flank, an extension which occupied the place of a few mass numbers.

The upper positive ion spectrum in Fig. 4 a represents the composition of kaolinite and/or metahalloysite outside the Ti-containing clouds. Only a little $\mathrm{Ti}$ is present here beside elements such as $\mathrm{Mg}, \mathrm{Al}, \mathrm{Si}, \mathrm{K}$ and $\mathrm{Fe}$. The middle and lower spectra were taken from microvolumes of Ti-containing clouds (Fig. 4b) and from the turbid secondary anatase (Fig. 4c). Si is absent in Fig. 4b, which is an uncommon situation; it was therefore chosen instead of a spectrum with Si that is normally represented in the amorphous materials of the clouds. The Ti content in the turbid anatase is higher than in the Ti-containing cloud; a result of LAMMA measurements which was also indicated by SEM-EDXRA experiments.

Other elements which were present in the Ti-containing clouds and the secondary anatase were $\mathrm{Al}, \mathrm{Si}$ and $\mathrm{Fe}$. This probably indicates that the turbidity in the secondary anatase is caused by morphological and/or chemical element remnants of the Ticontaining clouds from which this type of anatase is formed. A possible role for $\mathrm{Al}$ and $\mathrm{Si}$ was indicated by Weaver (1976) who found that an amorphous Si-Al compound can probably act as a cement for small $\mathrm{TiO}_{2}$ aggregates. This could also explain why secondary anatase is often present in the form of heterogeneous aggregates instead of individual grains, viz in thin sections of, for example, biotite which was weathered to kaolinite and/or metahalloysite (Bisdom, 1967b).

A peak of $\mathrm{Mn}$ was identified in Fig. $4 \mathrm{~b}$. $\mathrm{Na}, \mathrm{Mg}$ and $\mathrm{K}$ are also common and both $\mathrm{Na}$ and $\mathrm{K}$ are virtually always present in LAMMA spectra because of the extreme sensitivity to these elements. It is unlikely that $\mathrm{Na}$ is present, other than as a contamination, in the investigated part of the thin section. $\mathrm{K}$ and $\mathrm{Mg}$, however, which were not measured with SEM-EDXRA, may be present as trace elements.

A total of 53 shots were recorded during this experiment allowing the examination of various samples and different subjects. It also provided an insight into the sensitivity of LAMMA 500 analysis and the discrimination shown by the ion mass spectra after targets had been selected with the light microscope. It can be concluded that thin section examination with the LAMMA 500 is possible and advantageous when shooting on the visible edges with laser light at grazing incidence, or by applying laser milling to reach a spot to be analysed at some distance from the edge of the thin section. 

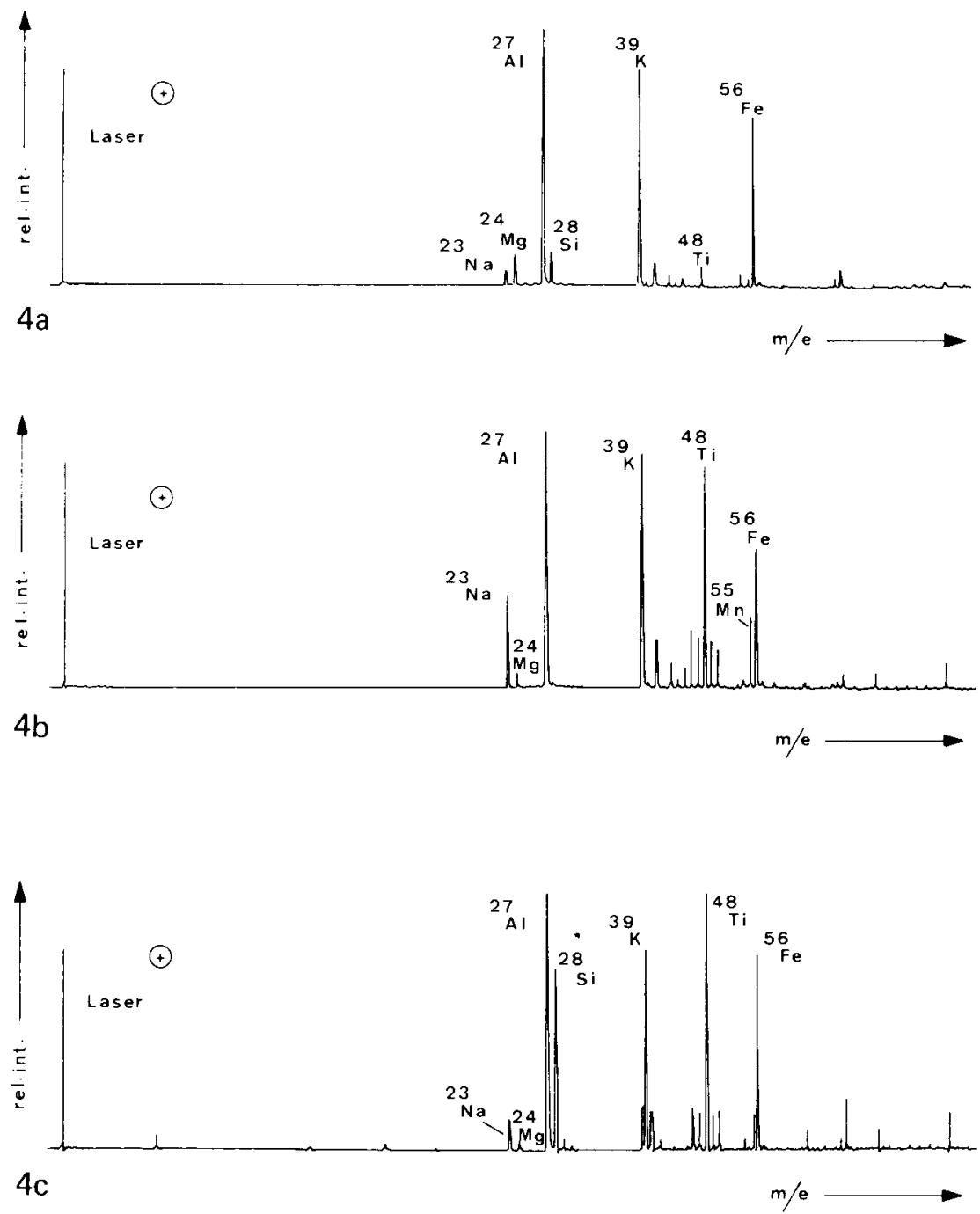

Fig. 4. LAMMA 500 spectra of positive ions from material in a thin section of soil, viz of kaolinite and/or metahalloysite (Fig. 4a), of material in Ti-containing clouds (Fig. 4b), and of turbid secondary anatase (Fig. 4c). Compare EDXRA X-ray spectra of Fig. 3c, 3d and 3e.

\section{Conclusions}

The laser microprobe mass analyzer (LAMMA 500) was used in the investigation of weathering biotite and the formed secondary minerals and amorphous materials. Of special interest were Ti-containing clouds of amorphous materials in which semicrystalline and crystalline minerals could develop; the latter being interpreted as sec- 
ondary anatase (Bisdom, 1967b). The present SEM-EDXRA and LAMMA analysis of the same material indicated that virtually no titanium was present outside the Ticontaining clouds, which themselves were situated in kaolinite and/or metahalloysite forming the weathering products of biotite in the original granite bedrock.

The Ti content seemed to increase with crystallinity according to LAMMA and SEM-EDXRA measurements. The secondary anatase $\left(\mathrm{TiO}_{2}\right)$, however, also contained more than trace element quantities of $\mathrm{Al}, \mathrm{Si}$ and $\mathrm{Fe}$. This probably indicates that the turbidity of the secondary anatase, observed with the petrographic microscope in the thin sections, is probably caused by remnants of the original Ti-containing clouds from which the secondary mineral was formed and which had a similar composition. Weaver (1976) studied the nature of $\mathrm{TiO}_{2}$ in Georgia kaolin and concluded that an amorphous $\mathrm{Si}-\mathrm{Al}$ compound could act as a cement for small anatase crystals which formed from an amorphous hydrous oxide gel consisting of $\mathrm{Ti}(\mathrm{OH})_{4}$. The kaolinite and/or metahalloysite contained only small amounts of $\mathrm{Ti}$ and consisted predominantly of $\mathrm{Al}, \mathrm{Si}$ and $\mathrm{Fe}$ with possibly trace elements of $\mathrm{Mg}$ and $\mathrm{K}$.

The LAMMA 500 proved to be an asset for the investigation of thin sections of soils when laser milling was applied to reach a spot to be analysed at some distance from the edge, or when shooting was done at grazing incidence on the visible edge of pieces of thin section which had previously been taken from the support glass and subsequently placed between sandwich grids for analysis with the machine. Semiquantitative measurements of the analysed microvolumes of soil material are still difficult, however, due to the comparatively recent introduction of the instrument. The LAMMA 500 can quickly test the presence of trace elements in a sample and the major elements found can be compared with those indicated by, for example, SEMEDXRA or EMA. The machine can also perform reconnaissance surveys in a thin section before IMMA investigation is started, especially because it can give information on trace elements. The prime aim of the construction of the LAMMA 500 was, however, to investigate microvolumes of ultra thin biological samples for their total chemical composition, including trace elements. Most soil samples, however, represent mixtures of extremely heterogeneous materials which also differ in hardness. For these a microtome is frequently not the ideal instrument and ion thinning is done instead, often with considerable difficulty and over extended periods of time. It can be advantageous to work with bulk material under such conditions, whereby the thicker thin section is analysed by EMA, SEM-EDXRA, LAMMA 500 or IMMA.

\section{References}

Bisdom, E. B. A., 1967a. The role of micro-crack systems in the spheroidal weathering of an intrusive granite in Galicia (NW Spain). Geologie en Mijnbouw, 46: 333-340.

Bisdom, E. B. A., 1967b. Micromorphology of a weathered granite near the Ria de Arosa (NW Spain). Leidse Geologische Mededelingen 37 (1966-1970). Ph.D. Thesis, Leiden, Netherlands, p. 33-67.

Bisdom, E. B. A., S. Henstra, A. Jongerius \& F. Thiel, 1975. Energy-dispersive X-ray analysis on thin sections and unimpregnated soil material. Neth. J. agric. Sci. 23(2): 113-125. 
Bisdom, E. B. A., S. Henstra, E. M. Hornsveld, A. Jongerius and A. C. Letsch, 1976. Wavelength and energy dispersive X-ray microanalysis with EMA and SEM-EDXRA on thin sections of soils. Neth. J. agric. Sci. 24(4): 209-222.

Bisdom, E. B. A., S. Henstra, A. Jongerius, J. D. Brown, A.P. van Rosenstiel \& D. J. Gras, 1977. Light and heavy element detection in thin sections of soils with the ion micropobe mass analyzer (IMMA). Neth. J. agric. Sci. 25(1)1-13.

Bisdom, E. B. A. \& A. Jongerius, 1978. SEM-EDXRA and/or IMMA analysis of cutans, an indurated horizon and clayified roots in thin sections of some Dutch soils. In: M. Delgado (Ed.), Soil micromorphology. Proceedings of the Fifth International Working Meeting on Soil Micromorphology (University of Granada, Spain, 1977), p. 741-754.

Bisdom, E. B. A. \& F. Thiel, 1981. Backscattered electron scanning images of porosities in thin sections of soils, weathered rocks and oil-gas reservoir rocks using SEM-EDXRA. In: E. B. A. Bisdom (Ed.), Submicroscopy of soils and weathered rocks. 1ste Workshop of the International Working-Group on Submicroscopy of Undisturbed Soil Materials (1980). Pudoc, Wageningen, Netherlands (in press).

Bresson, L. M., 1978. Nouvelles perspectives en microscopie integree: les lames ultra-minces et la microanalyse laser. In: M. Delgado (Ed.), Soil micromorphology. Proceedings of the Fifth International Working Meeting on Soil Micromorphology (University of Granada, Spain, 1977), p. 19-32.

Englert, P.\& U. Herpers, 1980. Isotopic anomalies of osmium from different deposits determined by the Laser Microprobe Mass Analyzer LAMMA. Inorg. Nucl. Chem. Lett. 16: 37-43.

Heinen, H. J., R. Wechsung, H. Vogt, F. Hillenkamp \& R. Kaufmann, 1978. Laser-Mikrosonden-Massen-Analysator LAMMA. Biotech. Umschau 2: 346-354.

Heinen, H. J., F. Hillenkamp, R. Kaufmann, W. Schröder \& R. Wechsung, in press a. LAMMA a new Laser Microprobe Mass Analyzer for biomedicine and material analysis. 6th International Symposium on Mass Spectrometry in Biochemistry and Medicine (Venice, 1979).

Heinen, H. J., S. Meier, H. Vogt and R. Wechsung, in press $b$. Laser induced mass spectrometry of organic and inorganic compounds with LAMMA. 8th Triannual International Mass Spectrometry Conference (Oslo, 1979).

Henstra, S., E. B. A. Bisdom, A. Jongerius \& F. Thiel, 1973. Energy dispersive analysis on thin sections of soils. First EDAX European Users Meeting (Liège, 1973). EDAX Editor 3(1): 5-6.

Hillenkamp, F., R. Kaufmann, R. Nitsche \& R. Unsöld, 1975. A high sensitivity Laser Microprobe Mass Analyzer. Appl. Phys. 8: 341-348.

Jongerius, A. and G. Heintzberger, 1963. The preparation of mammoth-sized thin sections. Soil Survey Pap. 1 (Netherlands Soil Survey Institute); 37 pp.

Jongerius, A. \& G. Heintzberger, 1975. Methods in soil micromorphology. A technique for the preparation of large thin section. Soil Survey Pap. 10 (Netherlands Soil Survey Institute); $48 \mathrm{pp}$.

Kaufmann, R., F. Hillenkamp, R. Nitsche, M. Schürmann, H. Vogt and R. Wechsung, 1978. The LAMMA-instrument: A new laser microprobe mass analyzer for biomedical purposes. Proc. 13th annual Conf. MAS (Ann Arbor), p. 16A-16E.

Kaufmann, R., F. Hillenkamp \& R. Wechsung, 1979. The Laser Microprobe Mass Analyzer (LAMMA): A new instrument for biomedical microprobe analysis. Med. Progr. Technol. 6: 109-121.

Kaufmann, R. \& P. Wieser, in press. Laser Microprobe Mass Analysis (LAMMA) in particle analysis. Liebl, H., 1975. Ion probe microanalysis. J. Phys. 8: 797-808.

Seydel, U. \& H. J. Heinen, 1979. First results on fingerprinting of single Mycobacteria cells with LAMMA. 6th International Symposium on Mass Spectrometry in Biochemistry and Medicine (Venice, Italy, 1979).

Weaver, C. E., 1976. The nature of $\mathrm{TiO}_{2}$ in kaolinite. Clays and Clay Minerals 24: 215-218.

Wechsung, R., F. Hillenkamp, R. Kaufmann, R. Nitsche, E. Unsöld \& H. Vogt, 1978. LAMMA - A new Laser-Microprobe-Mass-Analyzer. Microscopica Acta, Suppl. 2: 281-296. 